\title{
Designs on life
}

\section{Earlier this month, students from around the world locked horns in competition. Their challenge was to build functioning devices out of biological parts. Erika Check finds out how they got on.}

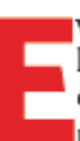
ven if you're thinking big, you usually have to start small. Especially, as a group of Swiss students found, when big means counting to infinity. The team was drawing up a blueprint for the world's first counting machine made entirely of biological parts. Although they had their sights on loftier numbers, they opted to go no higher than two. If the plan worked, it would be a proof-of-principle for a much larger tallying device.

The group, from the Federal Institute of Technology (ETH) in Zurich, was one of 17 teams unveiling their projects at the first international Intercollegiate Genetically Engineered Machine (iGEM) competition, held at the Massachusetts Institute of Technology (MIT) in Cambridge on 5 and 6 November. The event attracted students from all over the world to design and build machines made entirely from biological components such as genes and proteins. They drew up grand designs for bacterial Etch-a-Sketches, photosensitive t-shirts, thermometers and sensors. And if none of the designs succeeded completely, that was more because of the limitations of the nascent science of synthetic biology than any lack of enthusiasm, creativity or hard work.

Synthetic biology aims to merge engineering approaches with biology. Researchers working at the most basic level are copying simple biological processes, such as the production of a protein from a gene. They break the process down into its component elements, such as a gene and the pieces of DNA and other molecules that control its activity. They then string these elements together to build a module they know will behave in a particular way - say, oscillate between producing and not producing a protein, or produce a protein that can switch another module on or off.

It is these kinds of components - oscillators and switches - that engineers order from suppliers and link together to build more complex electronic circuits and machines. Synthetic biologists are trying to develop a similar armoury of biological components, dubbed BioBricks, that can be inserted into any genetic circuit to carry out a particular function. Scientists at MIT have established a Registry of Standard Biological Parts, a catalogue of BioBricks that theoretically can be ordered and plugged into a cell, just as resistors and transistors can be ordered and plugged into electronic circuitry ${ }^{1-3}$.

But it is hard to find scientists who are trained and interested in both biology and engineering to fuel the development of this new science. So, like true engineers, the founding synthetic biologists are trying to build their future colleagues
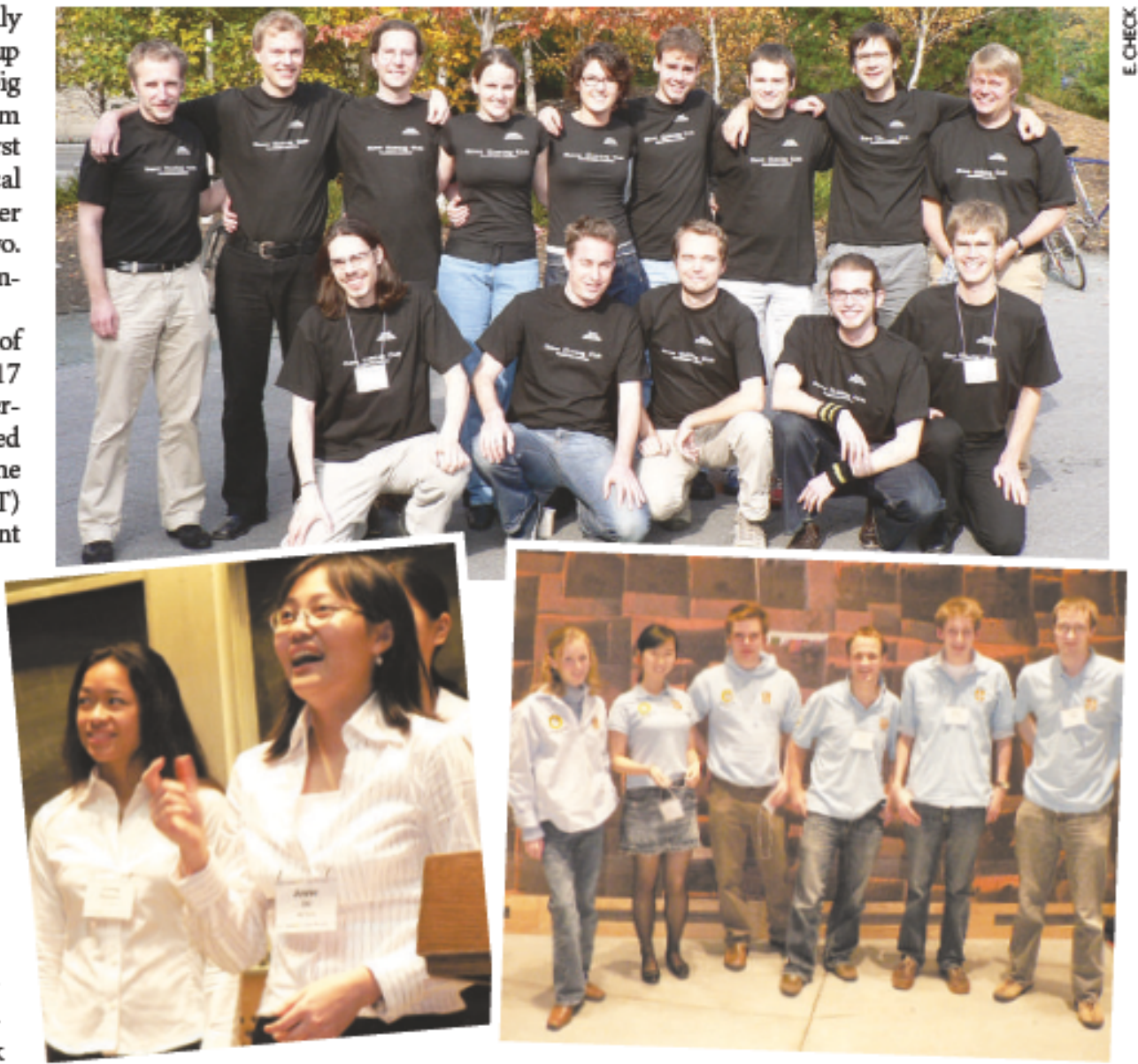

Bidding for glory: teams from the ETH in Zurich (top), Cambridge, UK, (bottom right) and Massachusetts at the first international Intercollegiate Genetically Engineered Machine competition.

from the ground up. To do so, they have commandeered a time-honoured engineering tradition: the student competition. The iGEM event began life as a project class for MIT students in 2003. Last year, it was thrown open to other US universities, and this year it went international. The organizers hope to attract 30 to 50 teams next year, including some from Asia.

\section{Competitive culture}

Much like the robot competitions that tap into students' desire to build something cool, the iGEM jamborees fire the participants' natural curiosity - hopefully encouraging biologists to learn something from engineers, and vice versa. "If you want to make something in this field, you can't just get some glue out and stick two cells together," says Randy Rettberg of MIT, who organized the competition. "You have to learn some biology to do it, and it's easy to do that during the competition because you know exactly why you're doing it."

This year, the teams presented an eclectic selection of designs. Students from the University of Cambridge, UK, tried to make a circuit that could control the movement of Escherichia coli bacteria. They aimed to engineer the bacteria to contain a switch governing their sensitivity to the sugar maltose. With the switch off, the microbes would ignore the sugar. Tripping the switch would make the bacteria sensitive to the sugar and induce them to move towards it. In the end, the group - like almost every other entrant - had trouble completing assembly of its genetic parts in time.

Many of the other students also tackled problems related to bacterial communication and motion. The team from Pennsylvania State University designed a bacterial relay race, which it hoped would bring synthetic biology into the realm of sports - an innovation that won it an award for the Best New Sport at the end of the competition.

A team from the University of Oklahomas Advanced Center for Genome Technology in Norman tried to exploit the sugar arabinose as 
an engine to drive bacterial motion. Teams from the University of Toronto and the University of California, San Francisco, built concepts for bacterial thermometers; and groups from Harvard, Toronto and Princeton designed bacterial illustrators and Etch-a-Sketches. Detection and sensing were also popular, with groups from Davidson College and MIT focusing in this area. And a lab at the California Institute of Technology tackled a problem raised at last year's event: designing biological memory.

Students from the University of Texas, Austin, demonstrated the world's first bacterial photography system. The team engineered a plate of $E$. coli so that they would respond to light and has since used the invention to take numerous photos, including shots of the group's adviser, Andrew Ellington (pictured) ${ }^{1}$.

\section{Piece by piece}

As well as helping students to bridge the divide between disciplines, the competition gave them firsthand experience of life in the lab. All hit snags assembling their parts into coherent ent genetic components of the circuits, stitch them together and get them to work in live cells. As Emanuel Nazareth from the University of Toronto reported, the students all learned one hard truth: "You can never allocate enough time for assembly."

This hints at a larger problem in synthetic biology. The field aims to build up a library of parts that can be interchanged in circuits with minimal effort. But that goal is not yet a reality as DNA sequencing and assembling technologies are still a bit too expensive and complex. ${ }^{\alpha}$ We're not organized at the community level around fabrication," says MIT's Drew Endy, one of the founders of the field and of the Registry of Standard Biological Parts. These hurdles need to be overcome before biological components will be as easy to deploy as their

Another learning experience was the reminder that, even stripped down to its basic components, biology can be complex and unpredictable. A team from the University of California, Berkeley, for instance, tried to design an entirely new way for cells to devices. It is still difficult to dissect the differengineering counterparts.
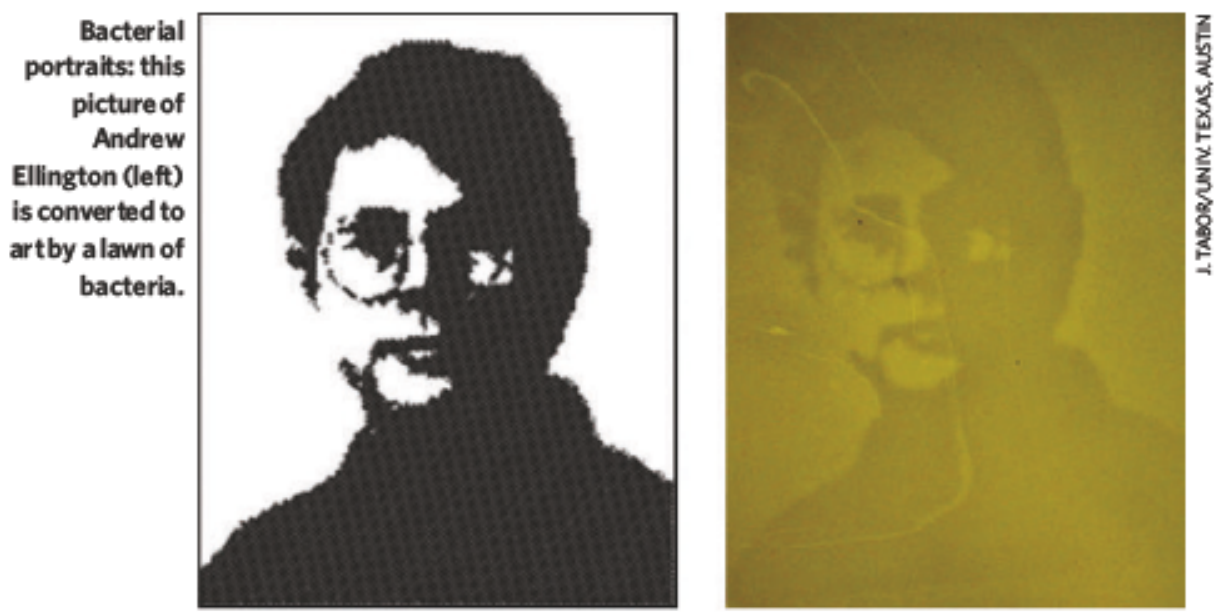

communicate. This is a potentially important because it would enable cells to send and receive information, forming interlocking cell circuits instead of relying on simple gene circuits built in single cells.

The team hoped to exploit a natural method used by bacteria to exchange genetic information, known as conjugation. In this, two bacteria connect their respective cell walls together using a structure called a pilus. The group managed to trigger the conjugation response with synthetic circuits. But the bacteria turned out to be so eager to join up that they did so in huge bunches - and once they did, it was hard to separate them. "They don't really conjugate one at a time," said team spokeswoman Melissa Li. "They can go, but they can't stop."

\section{The living end}

Scientists in synthetic biology expect to stumble over these unanticipated quirks. But the pioneers admit there is still a basic question that the field hasn't yet answered: will synthetic biology actually work? As Rettberg points out, there are a lot of sceptics. "There's this big question, which is: can you build simple biological systems out of interchangeable parts and make them work in living cells? ${ }^{\text {" he says. }}$ "We think you can, but there's a lot of people who think the other way and say biology is simply so complex you can't do it."

Given these concerns, it is no surprise that researchers have decided to keep things as

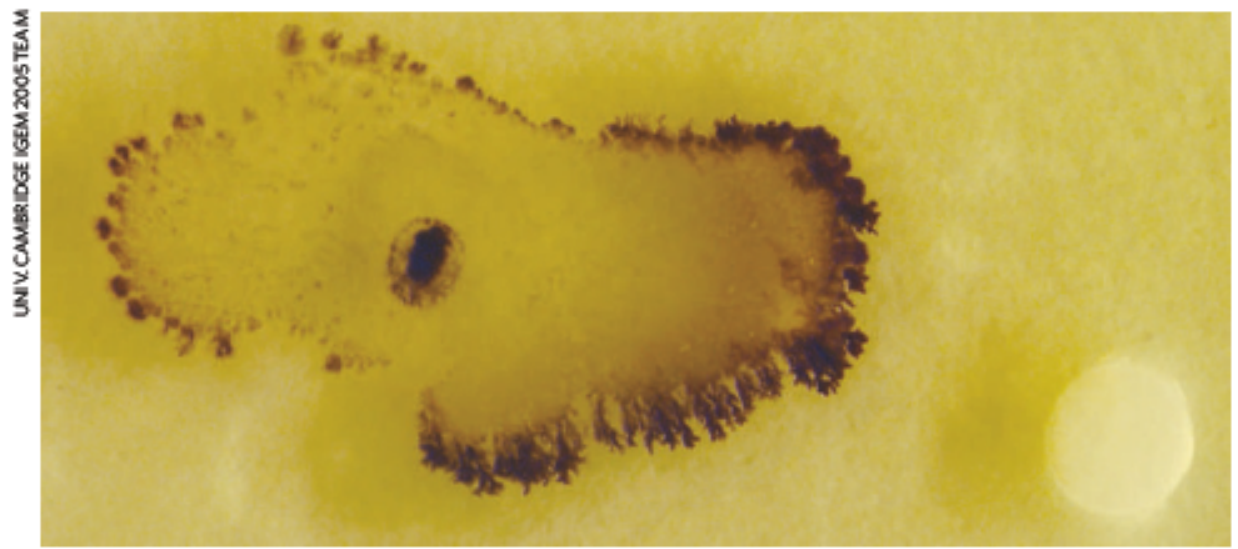

'Switched on' by an external trigger, Escherichia colli bacteria swim towards some maltose (bottom right). simple as possible, hence the ETH team's approach. As Robin Künzler said in introducing the project: "In the beginning we talked about counting to infinity, but we thought maybe we'd start by counting to two."

Despite this narrowed scope, the students faced a formidable challenge. They designed a a series of devices: the first takes in a signal, which is then passed to an event processor. This processor - a genetic circuit - splits the signal into two components. A third circuit does the counting and generates a read-out.

To design and execute its plan, the Zurich team enlisted student biologists, engineers and computer scientists. Together they successfully designed and tested the event processor. But they hit a snag when building the counter: the company making the genetic sequences was unable to deliver them on time. Other teams encountered similar problems. Researchers in the field hope that the proliferation of suppliers - including firms starting up in Europe - will address that problem, if not in time for next year's competition, then for later down the road.

But iGEM has been as much of a learning experience for the old hands as for the students. "We don't know how to engineer biological systems," says Endy. "You can't teach something you don't know how to do, so the students are helping us to figure it out." After all, the field is young, and growing pains are inevitable.

Nevertheless, the plan to engineer future synthetic biologists seems to be paying off. Several institutes taking part in iGEM have confirmed that they intend to run classes in the subject as a result. "It's been a very interesting approach and what it has done is provide very rapid uptake and a very rapid spread of this whole idea," says Gos Micklem, a geneticist at the University of Cambridge. ${ }^{\alpha}$ The competition is essentially stimulating every level, from graduate and undergraduate to senior people."

Erika Check is Nature's Washing ton biomedical correspondent.

1. Levskaya, A et al. Nature 438,441-442(2005).

2. Sprinzak, D.\& Elowitz, M.B.Nature 438,443-448(2005)

3 Endy, D. Nature 438,449-453 (2005).

http:/parts_mit_edu/wiki/index.php 